\title{
Overexpression of EGFR pathway-related genes in the circulation is highly correlated with EGFR mutations and overexpression in paired cancer tissue from patients with non-small cell lung cancer
}

\author{
CHUNG-CHI CHEN ${ }^{1-2^{*}}$, HUA-HSIEN CHIU ${ }^{2,3 *}$, LI-CHEN YEN $^{4}$, HUI-JEN CHANG ${ }^{1,4}$, \\ MING-SUNG CHANG ${ }^{5}$, JONG-RUNG TSAI ${ }^{6}$, YI-FANG CHEN ${ }^{7}$ and SHIU-RU LIN ${ }^{1,4}$ \\ ${ }^{1}$ School of Medical and Health Science, Fooyin University, Koahsiung; ${ }^{2}$ Division of Genomic Medicine, \\ Fooyin University Hospital, Pingtung; ${ }^{3}$ School of Environmental and Life Sciences, \\ Fooyin University, Koahsiung; ${ }^{4}$ Division of Medical Research; ${ }^{5}$ Department of Surgery, \\ Fooyin University Hospital, Pingtung; ${ }^{6}$ Division of Chest Medicine, Department of \\ Internal Medicine, Kaohsiung Medical University Hospital, Koahsiung; \\ ${ }^{7}$ Gene Target Technology Co. Ltd., Koahsiung, Taiwan, R.O.C.
}

Received May 15, 2009; Accepted July 9, 2009

DOI: $10.3892 /$ or 00000679

\begin{abstract}
Epidermal growth factor receptor (EGFR)-directed tyrosine kinase inhibitors (TKIs) have been established as a treatment option in patients with advanced non-small cell lung cancer (NSCLC). Clinically, PCR and RFLP are commonly used to evaluate the efficacy of TKIs, and these methods require cancer tissues to proceed. In the event a peripheral blood test is able to replace current evaluation methods, a greater clinical application advantage may be achieved. Therefore, in this study, we selected 30 EGFR pathway-related genes and constructed activated EGFR chips to identify overexpression of EGFR pathway-related genes from the peripheral blood of 72 NSCLC patients and 100 normal subjects. According to ROC curve analysis, the best chip interpretation cutoff value was 11 genes. Correlation analysis showed high significance among EGFR mutations, overexpression and the overexpression of EGFR pathway-related genes $(\mathrm{p}<0.0001)$. The potential application of this new technique may provide an accurate, instantaneous and convenient drug evaluation tool.
\end{abstract}

\section{Introduction}

The epidermal growth factor receptor (EGFR) is a membrane spanning glycoprotein that is normally under tight regulatory control. Activation of EGFR signaling may induce cell

Correspondence to: Dr Shiu-Ru Lin, School of Medical and Health Science, Fooyin University, 151 Chin-Hsueh Rd., Ta-Liao Hsiang, Kaohsiung County 831, Taiwan, R.O.C.

E-mail: srlin@ms2.hinet.net

${ }^{*}$ Contributed equally

Key words: epidermal growth factor receptor, non-small cell lung cancer migration, proliferation, invasion, angiogenesis and inhibition of apoptosis $(1,2)$. There are several mechanisms by which EGFR becomes oncogenic. i) Increased EGFR levels are prevalent in many cancer types leading to aberrant EGFR signaling. ii) EGFR is activated by autocrine and/or paracrine growth factor loops. iii) Heterodimerization with other EGFR family members and cross-talk with heterologous receptor systems serve as another mechanism for oncogenic activation of EGFR. iv) Defective receptor downregulation can also lead to cellular transformation, and v) the activating mutations promote EGFR signaling (3). Dysregulated EGFR is frequently associated with overexpression of the EGFR, and therefore has been implicated as a major mechanism in the pathogenesis of several epithelial malignancies including nonsmall cell lung (NSCLC), colorectal, gastric, breast and endometrial cancers (4). A number of studies have found that cancer patients with activated EGFR are more likely to experience a more aggressive progression and are correlated with poor clinical outcomes (4). Thus, the inhibition of EGFR cellular action has been intensely studied as a therapeutic target.

Gefitinib and erlotinib are small-molecule inhibitors of EGFR that prevent EGFR autophosphorylation and downstream signaling $(5,6)$. To date, clinical trials have been carried out in which patients have been treated with these drugs either as single agents or in combination with other anticancer drugs (7-9). Several significant factors affect sensitivity or resistance to tyrosine kinase inhibitors (TKIs) of EGFR and are associated with polymorphisms of EGFR, amplified EGFR gene and/or elevated EGFR mRNA expression (9-11). However, patient cancer tissues are required for clinical analysis of EGFR mutations, amplification and mRNA expression. When tissues are absent, efficacy prediction targets are lost.

Recently, we developed a colorimetric membrane array method which simultaneously detects the expression levels of a multiple mRNA marker in the peripheral blood used in 
circulating tumor cells (12). This platform of colorimetric membrane array test positively detected circulating activated K-ras in all of the NSCLC patients with K-ras mutations. Our previous results suggest that the K-ras oncogene membrane array can serve as a tool for the detection of the K-ras oncogene in the circulation (13). Activating mutations in the kinase domain of EGFR have been described in advanced NSCLC. These mutations also increase the kinase activity of the EGFR, leading to the hyperactivation of downstream genes, which in turn activates the intracellular signal transduction cascades, mainly the mitogen-activated protein kinase (MAPK), phosphoinositol 3 kinase (PI3K-AKT) and STAT pathways (14-16). In patients with these activating EGFR mutations, the single-agent response rates to either gefitinib or erlotinib [EGFR tyrosine kinase inhibitors (TKIs)] range from 60 to $80 \%$, which is remarkable in this disease (15).

Therefore, in this study, we used membrane array to assess the overexpression of EGFR pathway-related genes in the circulation of NSCLC patients. We also analyzed EGFR mutations, overexpression and overexpression of EGFR pathway-related genes in patient tissues and evaluated the consistency of outcomes with those from blood samples. The main goal of this study was to develop an innovative and sensitive diagnostic method for the rapid screening of peripheral blood of lung cancer patients. The potential application of this newly established method may provide an accurate and convenient means of monitoring the efficacy of therapies managing this malignancy.

\section{Materials and methods}

Specimen collections. This study was approved by the Institutional Review Board of Fooyin University Hospital, PingTung Christian Hospital and Kaohsiung Medical University Hospital. Seventy-two patients with pathologyconfirmed NSCLC who had undergone surgical resection or biopsy between January 2006 and December 2007, were enrolled in this study. All samples were collected immediately after surgical resection, frozen instantly in liquid nitrogen, and then stored at $-80^{\circ} \mathrm{C}$ until analyzed. Peripheral blood was collected from the patients before surgery and chemotherapy. Whole blood $(4 \mathrm{ml})$ was drawn into a tube with sodium citrate and preserved at $4{ }^{\circ} \mathrm{C}$ for activated EGFR detection. Written informed consent was obtained from all subjects and/or guardians for the use of their samples. Clinical stages and pathological features of the primary tumors were defined according to the criteria of the American Joint Commission on Cancer.

DNA extraction. All samples were collected immediately after surgical resection, frozen instantly in liquid nitrogen, and then stored at $-80^{\circ} \mathrm{C}$ until analyzed. Genomic DNA was isolated from frozen primary NSCLC and the paired normal tissues using proteinase-K (Stratagene, La Jolla, CA) digestion and the phenol/chloroform extraction procedure according to the method by Sambrook et al.

Direct sequencing. To identify mutations of the EGFR genes, the oligonucleotide primers for EGFR exons 18-21 (Table I) were used to perform polymerase chain reaction (PCR) analysis. The PCR products were purified by the Qiaex II Gel Extraction Kit and then subjected to sequencing using a double-strand cycle sequencing system. The purified products were then sequenced directly with T7 promoter/IRD800, which was a T7 promoter primer (Table I) labeled with a heptamethine cyanine dye or DNA polymerase incorporating IRD-labeled dATP for the sequencing reaction. Upon completion of the sequencing reaction, $4 \mathrm{ml}$ of formamide loading buffer was added to the reaction mixture. The samples were then heated to $95^{\circ} \mathrm{C}$ for $5 \mathrm{~min}$, snap-cooled, and loaded onto the sequencing gel. An automated DNA electrophoresis system (Model 4200; LI-COR) with a laser diode emission at $785 \mathrm{~nm}$ and fluorescence detection between 815 and $835 \mathrm{~nm}$ was used to detect and analyze the sequencing ladders. An aliquot of $1.5 \mathrm{ml}$ from each sequencing sample was loaded onto a sequencing gel $(41 \mathrm{~cm} \times 25 \mathrm{~cm} \times 0.2 \mathrm{~mm})$ consisting of $6 \%$ Long Ranger Matrix (AT Biochem; Malvern, PA, USA) and $7 \mathrm{M}$ urea in TBE buffer (133 $\mathrm{mM}$ Tris base, $44 \mathrm{mM}$ boric acid and $2.5 \mathrm{mM}$ EDTA, $\mathrm{pH} 9.0$ at $\left.50^{\circ} \mathrm{C}\right)$. Following the loading of samples, electrophoresis was carried out at a constant voltage of $2000 \mathrm{~V}$ with heating of the gel to $50^{\circ} \mathrm{C}$. Data collection and image analysis were performed using IBM486 (Model 90) with the Base Image IR software included with the model 4200 DNA sequencer.

RNA extraction and RT-PCR. Total RNA was purified from peripheral blood using a QIAmp ${ }^{\circledR}$ RNA Blood Mini Kit (Qiagen Inc., Valencia, CA) according to the manufacturer's instructions. First-strand cDNA was synthesized from total RNA by using an RT-PCR kit. Reverse transcription was carried out in a reaction mixture consisting of $1 \mathrm{X}$ Transcription Optimized 5X Buffer, $25 \mu \mathrm{g} / \mathrm{ml}$ Oligo(dT) 15 Primer, $100 \mathrm{mmol} / \mathrm{l}$ PCR Nucleotide Mix, $200 \mu \mathrm{mol} / \mathrm{l} \mathrm{M}$ MLV Reverse Transcriptase, and $0.5 \mu 1$ of Recombinant RNasin $^{\circledR}$ Ribonuclease Inhibitor (Promega Corp., USA). The reaction mixtures with RNA were incubated at $42^{\circ} \mathrm{C}$ for longer than $2 \mathrm{~h}$, heated to $95^{\circ} \mathrm{C}$ for $5 \mathrm{~min}$ and then stored at $4^{\circ} \mathrm{C}$ until analysis.

Northern blot analysis. Twenty micrograms of total RNA was denatured with $6.5 \%$ formamide and $50 \%$ formaldehyde for $15 \mathrm{~min}$ at $55^{\circ} \mathrm{C}$ and separated by electrophoresis through $1.2 \%$ agarose gels containing $1.1 \%$ formaldehyde. Then RNA was transferred onto a nylon membrane (Schleicher \& Schuell, Dassel, Germany) and fixed. The blots were successively hybridized with human EGFR cDNA. The hybridized filters were then washed twice with washing buffer (solution 1: $3 \mathrm{X}$ SSC, $0.5 \%$ SDS; solution II: $0.5 \mathrm{X}$ $\mathrm{SSC}, 0.1 \% \mathrm{SDS}$ ) at $65^{\circ} \mathrm{C}$ to wash off the unbound probe. The membrane was exposed to Kodak X-film at $-70^{\circ} \mathrm{C}$ for autoradiography. We used the GADPH or $\beta$-actin signal to normalize data for the above mRNA. All of the probes were confirmed by direct sequencing.

Oligo membrane array preparation. We used Vector NTI to design oligonucleotide probe sequences for the target genes, and $\beta$-actin served as an internal control (Table I). The newly synthesized oligonucleotide fragments were dissolved in DIwater to a concentration of $20 \mathrm{mM}$ and then applied to a 
Table I. Nucleotide sequences of primers used for DNA sequencing and probes for membrane array.

\begin{tabular}{|c|c|c|}
\hline Gene & \multicolumn{2}{|c|}{ Sequence } \\
\hline SOS & \multicolumn{2}{|c|}{ TCATGGTACCTGGTCTTGGGTTTGATGGACGAACACCAGGAGATTTTAGG } \\
\hline GRB & \multicolumn{2}{|c|}{ ACATCACCACAGGGGACCAGAAGTGGAGAGAAGACAGAGAGTTCTGCCGA } \\
\hline Raf & \multicolumn{2}{|c|}{ ACAAGGCTGTTTGTTTGTTTGTTTGTTAGAGAAACAAGGCTGGCCCTGCG } \\
\hline MEK & \multicolumn{2}{|c|}{ CATGGCAGTGAAGGGCTCTGGCTAGATTTGGATGTCAACTGCTGAGTTCT } \\
\hline ERK & \multicolumn{2}{|c|}{ TTGCTGTAAACAAACCCAGATGCAGGATCAACCCTTCTCAGCGGCAGTCG } \\
\hline VEGF & \multicolumn{2}{|c|}{ CCTGGGGGGACAGAACTAGTGGTTTCAATGGTGTGAGGACATAGGTCCTT } \\
\hline $\mathrm{COX} 2$ & \multicolumn{2}{|c|}{ ACAAACCCCGTACAGTTCTCTCTGAGGCACTAGCCTCTTTGCATCCATCT } \\
\hline PTGE2 & \multicolumn{2}{|c|}{ CATACACTTGCTGGGCCTCCTTCTCGTTGAGCATGAGCCAGTACTTATTG } \\
\hline $\mathrm{RAC}$ & \multicolumn{2}{|c|}{ CATCTGGGCCGTGAACTCCTCATCAAAATACCTGGTGTCAGTCTCCGACG } \\
\hline $\mathrm{RHO}$ & \multicolumn{2}{|c|}{ CAGAATGGAGAATGGACTAGCAACTGCTGAAGATGGGCTTGTCTGGCAAG } \\
\hline MEKK1 & \multicolumn{2}{|c|}{ GGCAAGAGTGCATCCTTTAAAGCTTGCACATGAGAGACTTGGAAACAATC } \\
\hline JNK & \multicolumn{2}{|c|}{ ATGATGGATGCTGAGAGCCATTGATCACTGCTGCACCTGTGCTAAAGGAG } \\
\hline PLC & \multicolumn{2}{|c|}{ CACTAAAGACAATTCCCAATCCTGAGTGGGTGGCAGAGACTCCTGCGATG } \\
\hline DAG & \multicolumn{2}{|c|}{ CTGGGTCCACCCACCCACCCTCAATCAGGGAATGGATACATTATTGCGAA } \\
\hline $\mathrm{PKC}$ & \multicolumn{2}{|c|}{ ACGCTTGGCTTGAAGTCTTACACCCCAGGCTCAACGATGGAGTTTGCATT } \\
\hline $\mathrm{PI} 3 \mathrm{~K}$ & \multicolumn{2}{|c|}{ GCTGTTGAACTGCAGTGCACCTTTCAAGCCGCCTTTGCACTGAATTTGCA } \\
\hline PIP2 & \multicolumn{2}{|c|}{ ACCTGAAGCTCTCAGAACGAATTGGTGGTAGAATGCAGCTATCGCAGCTC } \\
\hline PIP3 & \multicolumn{2}{|c|}{ AGCAGCACCAAAGCTTCTAGCTGGGTTGATACCAGTTCCAGTAATGGGGA } \\
\hline PTEN & \multicolumn{2}{|c|}{ CССТTCGGAAACСТСТСТTAGCCAACTGCAAACTTATCTGTTGCCACAAG } \\
\hline AKT & \multicolumn{2}{|c|}{ GCCAGCATACCATAGTGAGGTTGCATCTGGTGCCACCAGGTTGAACTGAG } \\
\hline $\mathrm{CDC} 42$ & \multicolumn{2}{|c|}{ GAGGATGTGAATCATTCCACAGATGTCTGTCTTCTAGCACCACCCCTCGT } \\
\hline SGK & \multicolumn{2}{|c|}{ TGATCAGGCATACCACACTCACACGACGGTTCACACAGCATATCCACAAG } \\
\hline $\mathrm{BAD}$ & \multicolumn{2}{|c|}{ AACATGCTCTGGGCTGTGAGGACAAGATGTTACGTAGTCAAGGCACAGCT } \\
\hline FKHR & \multicolumn{2}{|c|}{ GCCTTTCCCTGGACTTCACTGTTCTCAGAGAGCTACCAAGGATTCATGAC } \\
\hline GSK3B & \multicolumn{2}{|c|}{ CTTGACAGTTCTTGAGTGGTGAAGTTGAAGAGTGCAGGTGTGTCTCGCCC } \\
\hline MDM2 & \multicolumn{2}{|c|}{ GAAGCAGAACCACTTGAACACAGCCAGGAGGCAGAGGTTGCAGTGAGCCA } \\
\hline JAK2 & \multicolumn{2}{|c|}{ ATGAACACCAGCCCTCATGTGTGTAAAACATCACACAAGATGCCAAGGTA } \\
\hline STAT3 & \multicolumn{2}{|c|}{ GGGCGAACCCTGTTCATCTTAGAGAAGGTCGTCTCССССTTAATTCAGAG } \\
\hline STAT5B & \multicolumn{2}{|c|}{ TGTGGTTTGCAGGAACAAGGAGGAGAGAGAAGATAGAACGCAGAGAGCGA } \\
\hline PDK & CAGGATCTTGGCCTCTTAAA] & CTGGACTAACTGCCCATTCACA \\
\hline & Forward primer & Reverse primer \\
\hline EGFR exon 18 & GCTGAGGTGACCCTTGTCTC & ACAGCTTGCAAGGACTCTGG \\
\hline EGFR exon 19 & CCCAGTGTCCCTCACCTTC & CCACACAGCAAAGCAGAAAC \\
\hline EGFR exon 20 & TTCTGGCCACCATGCGA & CCGTATCTCCCTTCCCTGATTA \\
\hline EGFR exon 21 & TGATCTGTCCCTCACAGCAG & TCAGGAAAATGCTGGCTGAC \\
\hline
\end{tabular}

BioJet Plus 3000 nanoliter dispense system (BioDot, Irvine, $\mathrm{CA}$ ), which blotted sequentially the 30 target genes, $1 \mathrm{~TB}$ gene, and 1 housekeeping gene ( $($-actin) $(50 \mathrm{nl}$ per spot and $1.5 \mathrm{~mm}$ between spots) on a Nytran ${ }^{\circledR}$ SuperCharge nylon membrane in triplicate. DMSO was also dispensed onto the membrane as a blank control. After rapid drying and crosslinking procedures, preparation of the breast cancer diagnostic membrane array was carried out.

Preparation of biotin-labeled cDNA targets and hybridization. First-strand cDNA targets for hybridization were produced by using SuperScript II Reverse Transcriptase (Gibco-BRL) in the presence of biotin-labeled UTP (Roche Diagnostics
GmbH, Penzberg, Germany). After procedures of prehybridization and blocking, the gene chips were subjected to hybridization. The lifts were covered with the Express Hyb Hybridization Solution (BD Biosciences, Palo Alto, CA, USA) containing DIG-11-UTP-labeled cDNA probes, and then incubated with alkaline phosphatase-conjugated antidigoxigenin antibody (Roche Diagnostics). For hybridization, the arrays were incubated at $42^{\circ} \mathrm{C}$ for $12 \mathrm{~h}$ in a humidified chamber. After washing, the arrays were exposed to light. For signal detection, the gene chips were incubated in chromogen solution containing nitroblue-tetrazolium and 5bromo-4-chloro3-indoyl-phosphate (NBT/BCIP) (Zymed, CA, USA) for $15 \mathrm{~min}$. The hybridized arrays were then 
Table II. Results of the mutation, overexpression and membrane array analysis of EGFR.

\begin{tabular}{lrrrrr}
\hline \multirow{2}{*}{$\begin{array}{l}\text { EGFR } \\
\text { mutation }\end{array}$} & \multicolumn{2}{c}{$\begin{array}{c}\text { EGFR } \\
\text { overexpression }\end{array}$} & & \multicolumn{2}{c}{$\begin{array}{c}\text { Membrane } \\
\text { array analysis }\end{array}$} \\
\cline { 2 - 3 } & $\mathrm{P}$ & $\mathrm{N}$ & & $\mathrm{P}$ & $\mathrm{N}$ \\
\hline WT & 10 & 45 & & 16 & 39 \\
18,G719C & 4 & 0 & & 0 \\
18,E709K & 4 & 0 & & 0 \\
18,N700D & 1 & 0 & & 1 & 0 \\
20,V756M & 1 & 0 & & 0 \\
20,R766C & 1 & 0 & & 1 & 0 \\
20,V769M & 1 & 0 & & 1 & 0 \\
20,S768I & 2 & 0 & & 0 \\
20,R803W & 2 & 0 & & 0 \\
19,L747-T751 & 0 & 1 & & 1 & 0 \\
Total & 26 & 46 & & 33 & 39 \\
\hline
\end{tabular}

$\mathrm{N}$, negative; P, positive; WT, wild-type.

scanned with an Epson Perfection 1670 flat bed scanner (Seiko Epson Corp., Nagano-ken, Japan). Subsequent quantification analysis of the intensity of each spot was carried out by using AlphaEase ${ }^{\circledR}$ FC software (Alpha Innotech Corp., San Leandro, CA, USA). Spots consistently varying by a factor $\geq 2$ were considered to be differentially expressed. For each sample, membrane array hybridization was performed in triplicate to ensure the reproducibility of the results.

Statistical analysis. All data were analyzed by using the Statistical Package for the Social Sciences version 12.0 software (SPSS Inc., Chicago, IL). Correlations between EGFR mutant and wild-type and between EGFR mutations and EGFR activation were compared by using the Chi-square test. Receiver operating characteristic (ROC) curve analyses were carried out to determine cut-off value, sensitivity, and specificity for each mRNA marker. For a particular marker, a test was regarded as positive when the expression ratio of the marker was higher than its cut-off value.

\section{Results}

We collected 72 sets of peripheral blood, cancer tissue and neighboring normal tissue samples from lung cancer patients. In order to investigate EGFR mutations in lung cancer tissues, direct sequencing was performed on EGFR exons 1821 . The results showed that $17(23.61 \%)$ had mutations, including G719C, E709K and N700D of exon 18, L747T751 deletion of exon 19 and V756M, R766C, V769M, S768I, and R803W of exon 20. The mutation hotspots were close to $18 \mathrm{G} 719 \mathrm{C}$ and $18 \mathrm{E} 709 \mathrm{~K} ; 4$ cases were found on each of the two sites (Table II).

Northern blotting was used to analyze EGFR mRNA expression in samples of the lung cancer patients. There were $26(36.11 \%)$ samples exhibiting EGFR overexpression.
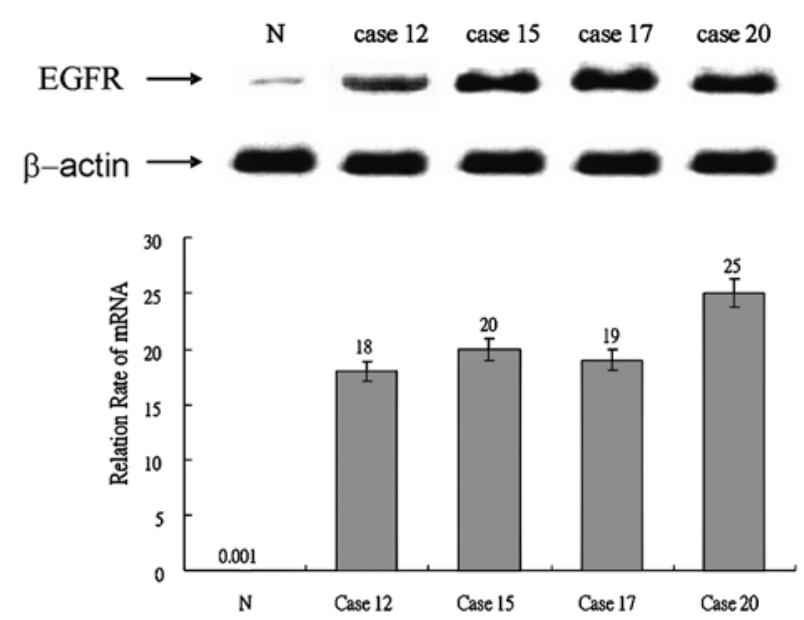

Figure 1. Northern blot analysis of EGFR mRNA expression in patient samples of lung cancer. EGFR mRNA was significantly overexpressed in cases $12,15,17$ and 20 compared to normal tissues after calibrating with ß-actin expression.

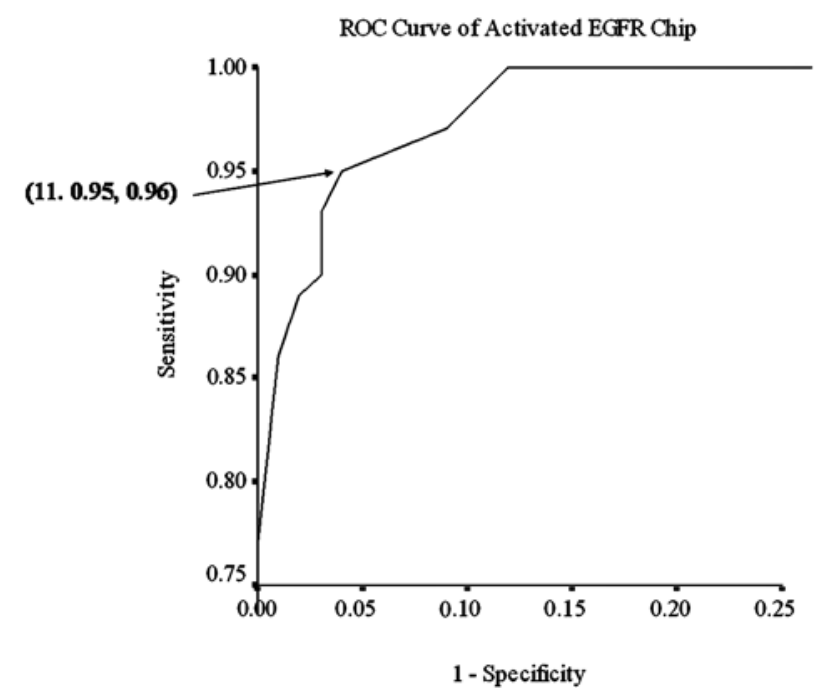

Figure 2. ROC curve analysis of membrane array data of 72 paired samples The optimal cutoff point for the number of differentially expressed genes was 11 . A membrane on which $\geq 11$ of the 30 genes were expressed 2 -fold higher than normal levels was considered to be positive and vice versa. At this cutoff point, the sensitivity and specificity of membrane arrays were 95 and $96 \%$, respectively.

Significant EGFR mRNA overexpression was observed in cases $12,15,17$ and 20 compared to normal tissues after calibrating with $\beta$-actin expression (Fig. 1).

On the other hand, we used the membrane array to analyze overexpression of EGFR pathway-related genes in 72 sets of peripheral blood and cancer tissue samples. We used the ROC curve to analyze 72 pairs of membrane array data, and determined that the optimal cutoff point for the number of differentially expressed genes was 11 (Fig. 2). In other words, the activated EGFR chip found $\geq 11$ positive signals out of the 30 genes, expressing 2 -fold higher than normal levels (Fig. 3). Based on this standard, among all 72 NSCLC peripheral blood samples, $33(45.83 \%)$ were positive with EGFR activation in the membrane array analysis (Table II). 


(A)
\begin{tabular}{|l|l|l|l|l|l|l|l|}
\hline SOS & GRB2 & Raf & MEK & ERK & VEGF & COX2 & PGE2 \\
\hline SOS & GRB2 & Raf & MEK & ERK & VEGF & COX2 & PGE2 \\
\hline SOS & GRB2 & Raf & MEK & ERK & VEGF & COX2 & PGE2 \\
\hline RAC & RHO & MEKK1 & JNK & PLC & DAG & PKC & PI3K \\
\hline RAC & RHO & MEKK1 & NNK & PLC & DAG & PKC & P13K \\
\hline RAC & RHO & MEKK1 & JNK & PLC & DAG & PKC & P13K \\
\hline PIP2 & PIP3 & PTEN & AKT & CDC42 & SGK & BAD & FKHR \\
\hline PIP2 & PIP3 & PTEN & AKT & CDC42 & SGK & BAD & FKHR \\
\hline PIP2 & PIP3 & PTEN & AKT & CDC42 & SGK & BAD & FKHR \\
\hline GSK3B & MDM2 & JAK2 & STAT3 & STAT5b & PDK & TB & B-actin \\
\hline GSK3B & MDM2 & JAK2 & STAT3 & STAT5b & PDK & TB & B-actin \\
\hline GSK3B & MDM2 & JAK2 & STAT3 & STAT5b & PDK & TB & B-actin \\
\hline
\end{tabular}

Table III. Correlation analysis between EGFR mutations and EGFR overexpression in lung cancer tissues.

\begin{tabular}{lcrrrr}
\hline & \multicolumn{2}{c}{$\begin{array}{c}\text { EGFR } \\
\text { mutations }\end{array}$} & & \\
\cline { 2 - 4 } & & WT & M & Total & P-value \\
\hline EGFR overexpression & $\mathrm{N}$ & 45 & 1 & 46 & 0.000 \\
& $\mathrm{P}$ & 10 & 16 & 26 & \\
Total & & 55 & 17 & 72 & \\
\hline
\end{tabular}

WT, wild-type; M, mutation; $\mathrm{N}$, negative; $\mathrm{P}$, positive.

(B)

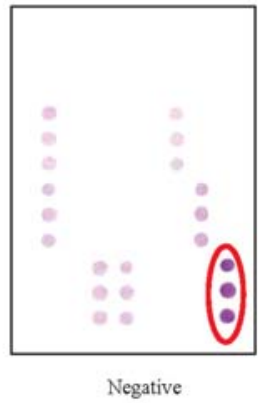

Figure 3. (A) Schematic representation of the membrane array with 30 target genes, 1 TB gene as a negative control, and 1 housekeeping gene ( $B$-actin) as an internal control. (B) Images of membrane array. Left diagram: experimental results of the lung cancer patients with non-activated EGFR. Right diagram: experimental results of the lung cancer patients with overexpression of EGFR pathway-related genes.

Furthermore, we analyzed the correlation among EGFR mutations, overexpression of cancer tissues, and overexpression of EGFR pathway-related genes in blood samples. The statistical analysis showed that $22.22 \%$ (16/72) of the cancer tissues had both EGFR overexpression and mutations (Table III). One hundred percent of the 17 patient samples with EGFR mutations (Table IV) and the 26 patient samples with EGFR overexpression (Table V) exhibited overexpression of EGFR pathway-related genes in both cancer tissue and peripheral blood analysis with the activated EGFR chip. A high correlation $(\mathrm{p}<0.0001)$ was found among these three expression levels (Table III-V). There were no statistical correlations between EGFR alterations and the clinical characteristics of the lung cancer patients including gender, size of tumor and metastasis (Table VI).

\section{Discussion}

Epidermal growth factor receptor (EGFR) is frequently amplified and/or mutated in a number of human tumors, and abnormal signaling from this receptor is believed to contribute to the malignant phenotype observed in these tumors (17). This has inspired the development of specific pharmacological inhibitors of the EGFR tyrosine kinase such as gefitinib, which disrupts EGFR kinase activity by reversibly binding within the ATP-binding pocket of the EGFR protein (18). Response rates of advanced NSCLC patients to these
Table V. Correlation analysis between EGFR overexpression and EGFR membrane array in lung cancer tissues.

\begin{tabular}{lrrrrrr}
\hline & \multicolumn{4}{c}{$\begin{array}{c}\text { EGFR } \\
\text { overexpression }\end{array}$} & & \\
\cline { 2 - 4 } & & $\mathrm{N}$ & $\mathrm{P}$ & & Total & P-value \\
\cline { 2 - 5 } EGFR membrane array & $\mathrm{N}$ & 39 & 0 & 39 & 0.000 \\
& $\mathrm{P}$ & 7 & 26 & 33 & \\
Total & & 46 & 26 & & 72 & \\
\hline
\end{tabular}

$\mathrm{N}$, negative; $\mathrm{P}$, positive.

drug treatments were $30-40 \%$ in Asian populations (19) and $10 \%$ in other ethnic groups (20).

Lynch et al (21), Paez et al (22) and Pao et al (23) reported that many NSCLC tumor tissues obtained from patients who responded to gefitinib or erlotinib treatment harbored somatic mutations in the tyrosine kinase domain of the EGFR gene. In addition, Dziadziuszko et al (10) and Hirsch et al (11) reported that patients with amplified EGFR gene and/or elevated EGFR mRNA expression have higher response rates and improved survival than those with low 
Table VI. Correlation analysis between the EGFR mutation, overexpression and membrane array in lung cancer tissues and clinical characteristics of the NSCLC patients.

\begin{tabular}{|c|c|c|c|c|c|c|c|c|c|}
\hline & \multicolumn{3}{|c|}{ EGFR mutations } & \multicolumn{3}{|c|}{ EGFR overexpression } & \multicolumn{3}{|c|}{ EGFR membrane array } \\
\hline & WT & M & P-value & $\mathrm{N}$ & $\mathrm{P}$ & P-value & $\mathrm{N}$ & $\mathrm{P}$ & P-value \\
\hline Total & 55 & 17 & & 46 & 26 & & 39 & 33 & \\
\hline \multicolumn{10}{|l|}{ Gender } \\
\hline Male & 34 & 8 & 0.281 & 29 & 13 & 0.281 & 27 & 15 & 0.041 \\
\hline Female & 21 & 9 & & 17 & 13 & & 12 & 18 & \\
\hline \multicolumn{10}{|l|}{ Histology } \\
\hline Adenocarcinoma & 36 & 14 & 0.07 & 29 & 21 & 0.133 & 24 & 26 & 0.206 \\
\hline Adenosquamous carcinoma & 2 & 2 & & 2 & 2 & & 2 & 2 & \\
\hline Squamous cell carcinoma & 17 & 1 & & 15 & 3 & & 13 & 5 & \\
\hline \multicolumn{10}{|l|}{ Tumor size (T) } \\
\hline $\mathrm{T} 1$ & 11 & 5 & 0.199 & 9 & 7 & 0.281 & 9 & 7 & 0.307 \\
\hline $\mathrm{T} 2$ & 22 & 10 & & 18 & 14 & & 14 & 18 & \\
\hline $\mathrm{T} 3$ & 11 & 1 & & 9 & 3 & & 7 & 5 & \\
\hline $\mathrm{T} 4$ & 11 & 1 & & 10 & 2 & & 9 & 3 & \\
\hline \multicolumn{10}{|l|}{ Lymph node (N) } \\
\hline No & 25 & 7 & 0.456 & 19 & 13 & 0.914 & 16 & 16 & 0.531 \\
\hline N1 & 5 & 4 & & 6 & 3 & & 4 & 5 & \\
\hline $\mathrm{N} 2$ & 15 & 4 & & 13 & 6 & & 13 & 6 & \\
\hline N3 & 10 & 2 & & 8 & 4 & & 6 & 6 & \\
\hline \multicolumn{10}{|l|}{ Metastasis (M) } \\
\hline M0 & 38 & 11 & 0.735 & 29 & 20 & 0.225 & 27 & 22 & 0.816 \\
\hline M1 & 17 & 6 & & 17 & 6 & & 12 & 11 & \\
\hline \multicolumn{10}{|l|}{ TNM stage } \\
\hline I & 16 & 5 & 0.885 & 11 & 10 & 0.429 & 10 & 11 & 0.614 \\
\hline II & 7 & 1 & & 6 & 2 & & 6 & 2 & \\
\hline III & 15 & 5 & & 12 & 8 & & 11 & 9 & \\
\hline IV & 17 & 6 & & 17 & 6 & & 12 & 11 & \\
\hline
\end{tabular}

WT, wild-type; M, mutation; N, negative; P, positive.

EGFR copy numbers and/or mRNA expression levels upon treatment with TKIs. Although the methods described may predict the efficacy of TKIs in NSCLC patients, clinically, cancer tissues are still required for EGFR mutation, amplification, and mRNA expression analysis. When tissues are absent, the prediction target for the efficacy is lost. In addition, cancer tissues cannot provide instantaneous evaluation of the efficacy after patient treatment with TKIs.

In our previous study, K-ras oncogene membrane array was successfully established; the downstream genes of K-ras were used to evaluate K-ras activity with blood samples of cancer patients. The sensitivity, specificity and accuracy of the diagnostic membrane array were $83.7,90.9$ and $86.8 \%$, respectively (12). Blood samples were easier to obtain and provided instant gene expression monitoring; EGFR autophosphorylation also activated downstream signaling pathways, including the Ras/Raf/mitogen-activated protein kinase (MAPK) and phosphatidylinositol 3'-kinase (PI3K)Akt pathways. Cappuzzo et al confirmed that phospho-Aktpositive patients had a better response rate than patients with
P-Akt-negative tumors to gefitinib treatment (24). Therefore, we used a membrane array to assess EGFR mutations and overexpression and the overexpression of EGFR downstream genes using NSCLC cancer tissues. The results were then compared to the blood analysis of these expression levels, showing high consistency. We believe that EGFR pathwayrelated genes in patient blood may be used to predict EGFR alterations in tissues as a therapeutic target predictor for drug efficacy.

In our study, rare mutations including S768I and V769M were found, and similar mutation patterns were also reported in Japanese NSCLC patients suggesting that these two mutation patterns might be detected only in Asian populations $(25,26)$. In addition, S768I and V769L mutations may be associated with resistance to gefitinib since such mutations are refractory to EGF-induced ubiquitination and degradation (27). In our study, small deletions centered around 5 codons in exon 19 (amino acid residues 747-751), similar to previous studies which found that deletions in exon 19 are the most common types of mutations identified in all of the large 
EGFR mutation studies of NSCLC patients, were clearly shown to be activated and correlated with sensitivity to tyrosine kinase inhibitors $(21,22,28,29)$.

We also found a high correlation between EGFR mutations and overexpression $(\mathrm{p}<0.0001)$. Similarly, Suzuki et al also confirmed that EGFR overexpression was correlated with EGFR TK domain mutations (30). In addition, many investigators have extensively studied associations between EGFR mutations and the downstream molecules such as pAkt and pMAPK in lung cancer cell lines and revealed that EGFR mutations are almost always accompanied by enhanced signaling of intracellular cascades in preclinical settings (24,31-33). Hosokawa et al also showed that EGFR mutations are related to phosphorylated Akt and that EGFR phosphorylation is closely correlated with EGFR protein expression (34). Cappuzzo et al observed that gefitinib sensitivity is associated with high EGFR protein expression (35). These studies indicate the possible use of NSCLC patient peripheral blood for the evaluation of TKI efficacy.

\section{References}

1. Grandis JR and Sok JC: Signaling through the epidermal growth factor receptor during the development of malignancy. Pharmacol Ther 102: 37-46, 2004.

2. Adamson ED: Developmental activities of the epidermal growth factor receptor. Curr Top Dev Biol 24: 1-29, 1990.

3. Zandi R, Larsen AB, Andersen P, Stockhausen MT and Poulsen HS: Mechanisms for oncogenic activation of the epidermal growth factor receptor. Cell Signal 19: 2013-2023, 2007.

4. Nicholson RI, Gee JM and Harper ME: EGFR and cancer prognosis. Eur J Cancer 37 (Suppl 4): 9-15, 2001.

5. Gadgeel SM, Ruckdeschel JC, Heath EI, Heilbrun LK, Venkatramanamoorthy R and Wozniak A: Phase II study of gefitinib, an epidermal growth factor receptor tyrosine kinase inhibitor (EGFR-TKI), and celecoxib, a cyclooxygenase-2 $(\mathrm{COX}-2)$ inhibitor, in patients with platinum refractory nonsmall cell lung cancer (NSCLC). J Thorac Oncol 2: 299-305, 2007.

6. Metro G, Finocchiaro G, Toschi L, et al: Epidermal growth factor receptor (EGFR) targeted therapies in non-small cell lung cancer (NSCLC). Rev Recent Clin Trials 1: 1-13, 2006.

7. Baselga J: Combining the anti-EGFR agent gefitinib with chemotherapy in non-small-cell lung cancer: how do we go from INTACT to impact? J Clin Oncol 22: 759-761, 2004.

8. Matar P, Rojo F, Cassia R, et al: Combined epidermal growth factor receptor targeting with the tyrosine kinase inhibitor gefitinib (ZD1839) and the monoclonal antibody cetuximab (IMC-C225): superiority over single-agent receptor targeting. Clin Cancer Res 10: 6487-6501, 2004.

9. Dutta PR and Maity A: Cellular responses to EGFR inhibitors and their relevance to cancer therapy. Cancer Lett 254: 165-177, 2007.

10. Dziadziuszko R, Witta SE, Cappuzzo F, et al: Epidermal growth factor receptor messenger RNA expression, gene dosage, and gefitinib sensitivity in non-small cell lung cancer. Clin Cancer Res 12: 3078-3084, 2006.

11. Hirsch FR, Varella-Garcia M, McCoy J, et al: Increased epidermal growth factor receptor gene copy number detected by fluorescence in situ hybridization associates with increased sensitivity to gefitinib in patients with bronchioloalveolar carcinoma subtypes: a Southwest Oncology Group Study. J Clin Oncol 23: 6838-6845, 2005

12. Chen YF, Wang JY, Wu CH, Chen FM, Cheng TL and Lin SR: Detection of circulating cancer cells with K-ras oncogene using membrane array. Cancer Lett 229: 115-122, 2005.

13. Chong IW, Chang MY, Sheu CC, et al: Detection of activated $\mathrm{K}$-ras in non-small cell lung cancer by membrane array: A comparison with direct sequencing. Oncol Rep 18: 17-24, 2007.

14. Chou WC, Huang SF, Yeh KY, et al: Different responses to gefitinib in lung adenocarcinoma coexpressing mutant- and wild-type epidermal growth factor receptor genes. Jpn J Clin Oncol 36: 523-526, 2006.
15. Sharma SV, Bell DW, Settleman J and Haber DA: Epidermal growth factor receptor mutations in lung cancer. Nat Rev 7: 169-181, 2007.

16. Sordella R, Bell DW, Haber DA and Settleman J: Gefitinibsensitizing EGFR mutations in lung cancer activate antiapoptotic pathways. Science 305: 1163-1167, 2004.

17. Pedersen MW, Pedersen N, Ottesen LH and Poulsen HS: Differential response to gefitinib of cells expressing normal EGFR and the mutant EGFRvIII. Br J Cancer 93: 915-923, 2005.

18. Arteaga CL and Johnson DH: Tyrosine kinase inhibitors ZD1839 (Iressa). Curr Opin Oncol 13: 491-498, 2001.

19. Fukuoka M, Yano S, Giaccone G, et al: Multi-institutional randomized phase II trial of gefitinib for previously treated patients with advanced non-small-cell lung cancer (The IDEAL 1 Trial) (corrected). J Clin Oncol 21: 2237-2246, 2003.

20. Kris MG, Natale RB, Herbst RS, et al: Efficacy of gefitinib, an inhibitor of the epidermal growth factor receptor tyrosine kinase, in symptomatic patients with non-small cell lung cancer: a randomized trial. JAMA 290: 2149-2158, 2003.

21. Lynch TJ, Bell DW, Sordella R, et al: Activating mutations in the epidermal growth factor receptor underlying responsiveness of non-small-cell lung cancer to gefitinib. N Engl J Med 350: 2129-2139, 2004.

22. Paez JG, Janne PA, Lee JC, et al: EGFR mutations in lung cancer: correlation with clinical response to gefitinib therapy. Science 304: 1497-1500, 2004.

23. Pao W, Miller V, Zakowski M, et al: EGF receptor gene mutations are common in lung cancers from 'never smokers' and are associated with sensitivity of tumors to gefitinib and erlotinib. Proc Natl Acad Sci USA 101: 13306-13311, 2004.

24. Cappuzzo F, Magrini E, Ceresoli GL, et al: Akt phosphorylation and gefitinib efficacy in patients with advanced non-small-cell lung cancer. J Natl Cancer Inst 96: 1133-1141, 2004.

25. Huang SF, Liu HP, Li LH, et al: High frequency of epidermal growth factor receptor mutations with complex patterns in nonsmall cell lung cancers related to gefitinib responsiveness in Taiwan. Clin Cancer Res 10: 8195-8203, 2004.

26. Kosaka T, Yatabe Y, Endoh H, Kuwano H, Takahashi T and Mitsudomi T: Mutations of the epidermal growth factor receptor gene in lung cancer: biological and clinical implications. Cancer Res 64: 8919-8923, 2004.

27. Asahina H, Yamazaki K, Kinoshita I, Yokouchi H, DosakaAkita $\mathrm{H}$ and Nishimura M: Non-responsiveness to gefitinib in a patient with lung adenocarcinoma having rare EGFR mutations S768I and V769L. Lung Cancer 54: 419-422, 2006.

28. Kosaka T, Yatabe Y, Endoh H, et al: Analysis of epidermal growth factor receptor gene mutation in patients with non-small cell lung cancer and acquired resistance to gefitinib. Clin Cancer Res 12: 5764-5769, 2006.

29. Shigematsu H, Lin L, Takahashi T, et al: Clinical and biological features associated with epidermal growth factor receptor gene mutations in lung cancers. J Natl Cancer Inst 97: 339-346, 2005.

30. Suzuki M, Shigematsu H, Hiroshima K, et al: Epidermal growth factor receptor expression status in lung cancer correlates with its mutation. Hum Pathol 36: 1127-1134, 2005.

31. Han SW, Kim TY, Hwang PG, et al: Predictive and prognostic impact of epidermal growth factor receptor mutation in nonsmall-cell lung cancer patients treated with gefitinib. J Clin Oncol 23: 2493-2501, 2005.

32. Hirsch FR, Varella-Garcia M, Bunn PA Jr, et al: Molecular predictors of outcome with gefitinib in a phase III placebocontrolled study in advanced non-small-cell lung cancer. J Clin Oncol 24: 5034-5042, 2006.

33. Cappuzzo F, Ligorio C, Janne PA, et al: Prospective study of gefitinib in epidermal growth factor receptor fluorescence in situ hybridization-positive/phospho-Akt-positive or never smoker patients with advanced non-small-cell lung cancer: The ONCOBELL Trial. J Clin Oncol 25: 2248-2255, 2007.

34. Hosokawa S, Toyooka S, Fujiwara Y, et al: Comprehensive analysis of EGFR signaling pathways in Japanese patients with non-small cell lung cancer. Lung Cancer (In press).

35. Cappuzzo F, Hirsch FR, Rossi E, et al: Epidermal growth factor receptor gene and protein and gefitinib sensitivity in non-smallcell lung cancer. J Natl Cancer Inst 97: 643-655, 2005. 